\title{
Análise da dinâmica espacial da ocupação das terras e seus conflitos de uso no perímetro urbano de Santa Maria - RS (1975 - 2002)
}

\author{
Spatial dynamic analysis of the land occupation and their conflicts of use in the urban perimiter of \\ Santa Maria - RS (1975 - 2002)
}

\author{
Fabrício de Araújo Pedron ${ }^{1}$ Ricardo Simão Diniz Dalmolin ${ }^{1}$ Antonio Carlos de Azevedo ${ }^{1}$ \\ Marcio Ramos Botelho ${ }^{2}$ Alessandro Samuel Rosa ${ }^{3}$
}

\section{RESUMO}

As cidades brasileiras, em escala variável, têm apresentado problemas resultantes do uso indevido do espaço urbano, principalmente, em relação aos recursos naturais. Neste caso, o estudo da dinâmica de uso das terras é importante na compreensão dos processos ocorridos no ambiente urbano. $O$ objetivo deste trabalho foi analisar a dinâmica espacial $e$ temporal de ocupação das terras em áreas urbanas de Santa Maria - RS, determinando seus conflitos de uso através do Sistema de Avaliação do Potencial de Uso Urbano das Terras (SAPUT), considerando informações do período de 1975 a 2002. O uso urbano das terras cresceu de 9\%, em 1975, para $33 \%$, em 2002. Os conflitos de uso das terras aumentaram de $19 \%$, em 1975, para 37\%, em 1995, reduzindo para $33 \%$ em 2002. Os principais problemas de uso indevido das terras se relacionam à fragilidade do material geológico e do recurso solo para uso em construções e agricultura urbana.

Palavras-chave: classificação das terras, pedologia, sensoriamento remoto.

\section{ABSTRACT}

The Brazilian cities have been facing problems due to the improper use of the urban space, mainly, related to the natural resources. In this case, the study of the dynamics of land use is important in the understanding of the processes occured in the urban environment. This research was aimed at analysing the space and temporal dynamics of land occupation in urban areas of Santa Maria - RS, Brazil, determining the conflicts of the land use through the Urban Land Use Potencial System (SAPUT), considering information from 1975 to 2002. The urban land use raised from 9\% in 1975 to 33\% in 2002. The conflicts of land use have increased from $19 \%$ in 1975, to $37 \%$ in 1995, reducing to $33 \%$ in 2002. The main problems of the improper land use are linked to the fragility of the geological material and soil resource when used for constructions and urban agriculture.

Key words: land use classification, pedology, remote sensing.

\section{INTRODUÇÃO}

Embora o processo de urbanização seja um fenômeno mundial, no Brasil ocorre de forma mais intensa, semelhantemente aos demais países em desenvolvimento. A expansão urbana brasileira tem sido resultado do rápido processo de industrialização e do crescimento demográfico, com um incremento forte após a década de 70 (CALLAI, 1993; ROSSATO, 1993; DA COSTA \& CINTRA, 1999). Os números do Censo 2000 mostram que $81 \%$ da população brasileira reside em áreas urbanas e que este processo é irreversível, registrando-se o aumento de 5\% em relação ao Censo de 1991 (BRASIL, 2004).

Atualmente, em escala variável, as cidades brasileiras apresentam problemas comuns, que foram agravados, ao longo dos anos, pela falta de planejamento e controle dos processos ocorridos no espaço urbano (BRASIL, 2004). A falta de cuidados com os recursos naturais, somados ao descaso pelas condições de vida das populações pobres, são os grandes responsáveis pela degradação das cidades, afetando, de alguma maneira, todos os extratos sociais,

'Departamento de Solos, Universidade Federal de Santa Maria (UFSM), Campus Universitário, 97105-900, Santa Maria, RS, Brasil. E-mail: fapedron@mail.ufsm.br. Autor para correspondência.

${ }^{2}$ Departamento de Solos, Faculdade de Agronomia Eliseu Maciel (FAEM), Universidade Federal de Pelotas (UFPel), Pelotas, RS, Brasil. ${ }^{3}$ Curso de Agronomia, UFSM, Santa Maria, RS, Brasil. 
necessitando-se de uma abordagem multidisciplinar para sua solução (DA COSTA \& CINTRA, 1999; EL ARABY, 2002).

Em relação ao município de Santa Maria $\mathrm{RS}$, o processo de urbanização intensificou-se a partir dos anos 60, dobrando sua população em apenas duas décadas. A taxa de urbanização de Santa Maria aumentou de $66 \%$, em 1960, para $95 \%$, em 2000 (IBGE, 2005). Este caráter urbano de Santa Maria trouxe consigo uma infinidade de problemas sócio ambientais, resultantes da falta de organização do espaço ocupado pela cidade, o qual é caracterizado pela expansão desordenada, por vezes, sobre áreas impróprias, que oferecem risco à ocupação humana (BERGER, 2001; ROBAINA et al., 2001).

Neste contexto, o estudo da dinâmica de uso das terras é fundamental para o entendimento dos processos ocorridos no ambiente urbano. A análise multitemporal do uso das terras tem se mostrado importante na determinação dos conflitos de uso dos recursos naturais, sendo muito utilizada no diagnóstico e monitoramento das condições ambientais das cidades em todo o mundo (THOMLINSON \& RIVERA, 2000; LÓPEZ et al., 2001; HATHOUT, 2002). Com o avanço da tecnologia, informações de sensoriamento remoto e geoprocessamento tornaram-se grandes aliadas no estudo temporal e espacial do uso das terras. No caso de áreas urbanas, outras ferramentas, como sistemas de classificação de terras, também já estão disponíveis (PEDRON, 2005; PEDRON et al., 2006), auxiliando na organização adequada do ambiente.

Os objetivos desse trabalho foram analisar a dinâmica de ocupação das terras no perímetro urbano de Santa Maria, RS, através da caracterização do seu uso em diferentes épocas, e determinar os conflitos de uso das terras para cada período observado entre os anos de 1975 e 2002.

\section{MATERIAL E MÉTODOS}

Este trabalho foi desenvolvido no perímetro urbano do município de Santa Maria, Rio Grande do Sul, o qual possui 12.548 hectares. Santa Maria localizase na região fisiográfica da Depressão Central, próxima ao rebordo do Planalto Riograndense, a $29^{\circ} 43^{\prime}$ de latitude sul e $53^{\circ} 49^{\prime}$ de longitude oeste. O clima local apresenta precipitação média de $1700 \mathrm{~mm}^{2} \mathrm{ano}^{-1}$, temperatura média anual de $18^{\circ} \mathrm{C}$, média das máximas do mês mais quente de $32^{\circ} \mathrm{C}$ e das mínimas do mês mais frio de $9^{\circ} \mathrm{C}$, sendo, segundo a classificação de Köppen, do tipo Cfa (BURIOL et al., 1979).

O estudo temporal do uso das terras do perímetro urbano de Santa Maria (PUSM) foi efetuado através da análise de fotografias aéreas do ano de 1975, na escala 1:110.000, ampliadas até a escala 1:50.000, e de imagens multiespectrais do sensor TM (Landsat 5) dos anos de 1987 e 1995 e do sensor ETM+ (Landsat 7) do ano de 2002, com resolução espacial de 30 metros. Os diversos Planos de Informação (PI) considerados neste trabalho foram produzidos e manejados utilizando-se técnicas de sensoriamento remoto e geoprocessamento digital, através do aplicativo Spring - Sistema de Processamento de Informações Georeferenciadas (CAMARA et al., 1996), versão 4.0, desenvolvido pelo INPE - Instituto Nacional de Pesquisas Espaciais.

Os mapas de uso atual das terras para os períodos de 1987, 1995 e 2002 foram gerados a partir da classificação multiespectral não-supervisionada das respectivas imagem orbitais. O método de classificação utilizado foi o "pixel a pixel”, através do classificador estatístico "MAXVER" (máxima verossimilhança), conforme INPE (2003). Foram estabelecidas cinco classes de uso: urbano, floresta (nativa e plantada), agricultura anual (culturas anuais), campo natural (pastagens naturais e vegetação secundária) e corpos d'água (lagos e barragens). Pequenos erros de classificação foram parcialmente corrigidos pela reambulação temática e pela comparação com fotografias aéreas do ano de 1996, na escala 1:60.000.

O mapa de uso da terra de 1975 foi gerado pela classificação supervisionada da fotografia aérea, a qual foi digitalizada utilizando-se os mesmos métodos das imagens multiespectrais. No entanto, a classe agricultura anual foi suprimida nesta classificação devido à existência de uma única banda espectral e, conseqüentemente, de maior dificuldade de separação digital dos diferentes alvos da fotografia, sendo suas áreas incluídas na classe campo natural.

A classe urbano representa todos os materiais artificiais presentes no ambiente urbano, sendo a definição de área urbana neste trabalho não atrelada à legislação local, que considera a presença de determinadas estruturas ou a localização de um alvo, mas sim unicamente ao valor espectral de cada objeto imageado e agrupado nesta classe.

O mapa de potencial de uso das terras (Figura 1) foi gerado pelo Sistema de Avaliação do Potencial de Uso Urbano das Terras - SAPUT (PEDRON, 2005; PEDRON et al., 2005; PEDRON et al., 2006), utilizando informações do levantamento semidetalhado de solos, além de dados referentes à geologia, às áreas de preservação permanente, ao clima, ao relevo e aos recursos hídricos da área de estudo, gerando classes de potencial de uso urbano para os 


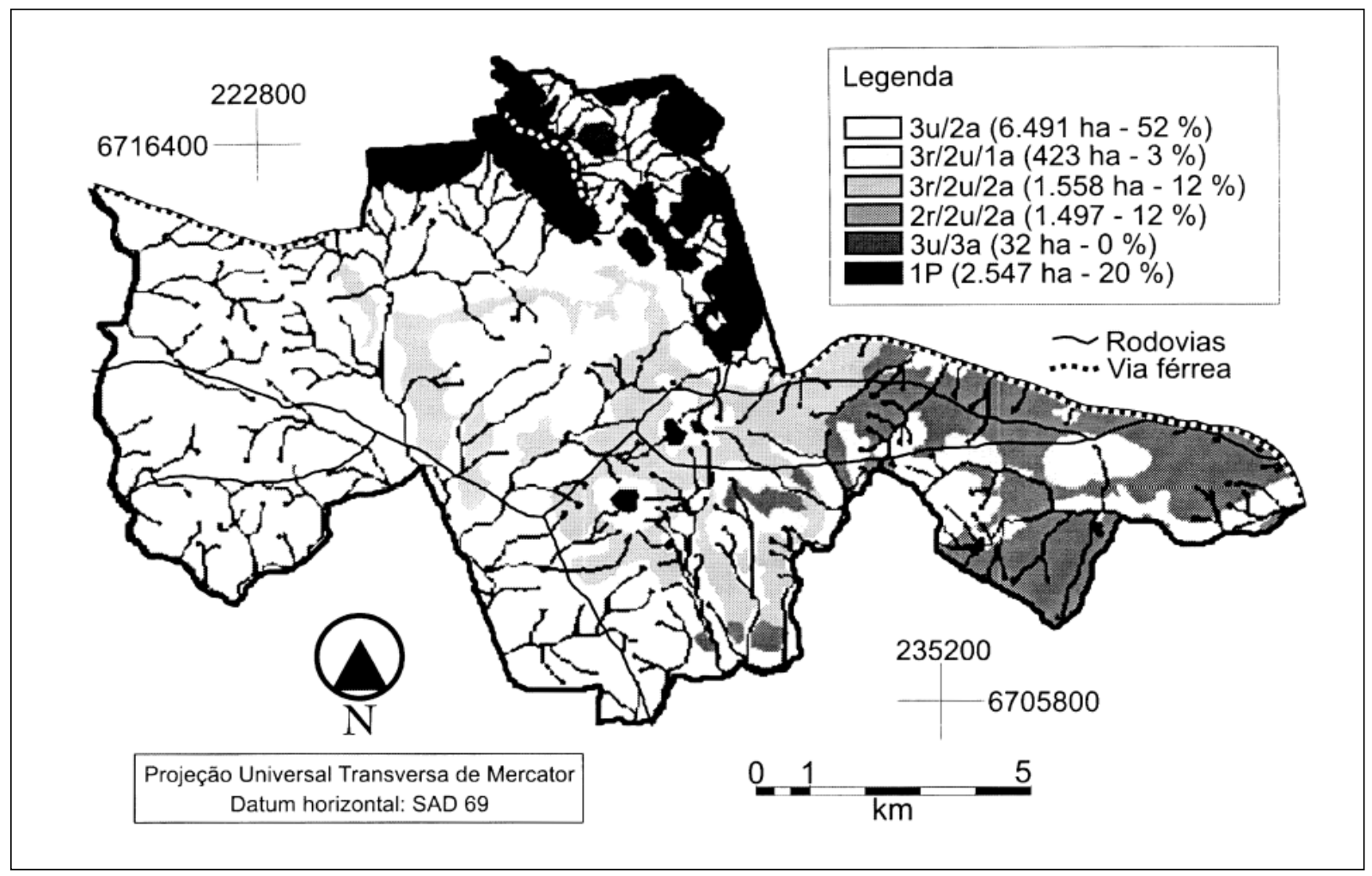

Figura 1 - Mapa de potencial de uso urbano das terras do perímetro urbano de Santa Maria, RS (PEDRON et al., 2006).

Legenda:

$3 \mathrm{u}$ - grupo construções urbanas, potencial restrito ao subgrupo áreas verdes e recreativas;

$2 \mathrm{u}$ - grupo construções urbanas, potencial restrito ao subgrupo comercial e residencial;

$3 \mathrm{r}$ - grupo descarte de resíduos, potencial restrito ao subgrupo resíduos orgânicos atóxicos;

2r - grupo descarte de resíduos, potencial restrito ao subgrupo resíduos inorgânicos atóxicos;

3a - grupo agricultura urbana, potencial restrito ao subgrupo silvicultura e/ou pastagem natural;

2a - grupo agricultura urbana, potencial restrito ao subgrupo olericultura e fruticultura;

1 a - grupo agricultura urbana, potencial restrito ao subgrupo lavoura anual;

$1 \mathrm{P}$ - potencial adequado para o grupo preservação ambiental.

grupos descarte de resíduos, construções urbanas, agricultura urbana e preservação ambiental, conforme PEDRON et al. (2006). No SAPUT, as classes de potencial de uso urbano (adequado, restrito e inadequado) são determinadas pela análise dos fatores restritivos considerados em cada grupo de uso e em seu posterior enquadramento nos subgrupos.

Os PI de uso das terras foram sobrepostos ao PI potencial de uso urbano das terras dando origem aos mapas de conflitos de uso das terras para cada período analisado. As análises de correlação e regressão entre dados demográficos (IBGE, 2005) e a expansão de áreas urbanas foram realizadas através do aplicativo estatístico "Statistica", versão 6 (STAT SOFT, Inc., 2001).

\section{RESULTADOS E DISCUSSÕES}

Os dados obtidos pela geração dos PI uso das terras para os períodos avaliados são apresentados na tabela 1. Em 1975, 9\% do PUSM pertencia à classe urbano, aumentando acentuadamente em 12 anos, chegando, em 1987, a 28\%. Se forem considerados os dados dos censos realizados no município (IBGE, 2005), verifica-se que, próximo a este período, nas décadas de 60 a 80, ocorreu aumento da população de aproximadamente 80 mil para 160 mil habitantes. Nesse caso, observa-se um crescimento horizontal da cidade, onde novas áreas são tomadas pelas construções urbanas. Já os dados de 1995 e 2002 apontam uma ocupação urbana de 32 e $33 \%$ do PUSM. Considerandose o crescimento populacional de 1987 a 2002, percebe- 
Tabela 1 - Áreas dos PI uso das terras e áreas dos PI conflitos de uso das terras, nos períodos de 1975, 1987, 1995 e 2002, para o perímetro urbano de Santa Maria, RS.

\begin{tabular}{|c|c|c|}
\hline \multirow{2}{*}{ Planos de informação } & \multicolumn{2}{|c|}{ Áreas* } \\
\hline & ha & $\%$ \\
\hline \multicolumn{3}{|l|}{ Uso das terras 1975} \\
\hline Urbano & 1.102 & 9 \\
\hline Floresta & 1.435 & 11 \\
\hline Agricultura anual & $-^{+}$ & - \\
\hline Campo natural & 9.948 & 79 \\
\hline \multicolumn{3}{|l|}{ Uso das terras 1987} \\
\hline Urbano & 3.475 & 28 \\
\hline Floresta & 1.438 & 11 \\
\hline Agricultura anual & 360 & 3 \\
\hline Campo natural & 7.207 & 57 \\
\hline \multicolumn{3}{|l|}{ Uso das terras 1995} \\
\hline Urbano & 3.972 & 32 \\
\hline Floresta & 1.578 & 13 \\
\hline Agricultura anual & 992 & 8 \\
\hline Campo natural & 5.929 & 47 \\
\hline $\begin{array}{l}\text { Corpos d'água } \\
\text { Uso das terras } 2002\end{array}$ & \multicolumn{2}{|c|}{ Uso das terras 2002} \\
\hline Urbano & 4.148 & 33 \\
\hline Floresta & 2.533 & 20 \\
\hline Agricultura anual & 564 & 4 \\
\hline Campo natural & 5.221 & 42 \\
\hline \multicolumn{3}{|l|}{ Conflitos de uso 1975} \\
\hline Adequado & 1.193 & 10 \\
\hline Subutilizado & 8.993 & 72 \\
\hline $\begin{array}{l}\text { Inadequado } \\
\text { Conflitos de uso } 198\end{array}$ & \multicolumn{2}{|c|}{ Conflitos de uso 1987} \\
\hline Adequado & 1.906 & 15 \\
\hline Subutilizado & 6.575 & 52 \\
\hline $\begin{array}{l}\text { Inadequado } \\
\text { Conflitos de uso } 199\end{array}$ & 4.067 & 32 \\
\hline Adequado & 2.328 & 19 \\
\hline Subutilizado & 5.637 & 45 \\
\hline $\begin{array}{l}\text { Inadequado } \\
\text { Conflitos de uso } 200\end{array}$ & \multicolumn{2}{|c|}{ Conflitos de uso 2002} \\
\hline Adequado & 2.729 & 22 \\
\hline Subutilizado & 5.702 & 45 \\
\hline Inadequado & 4.117 & 33 \\
\hline
\end{tabular}

*A soma das porcentagens pode não igualar a 100 devido a erros de arredondamentos.

${ }^{+}$No PI uso das terras de 1975 , a classe agricultura anual foi incluída na classe campo natural, devido à dificuldade de classificar corretamente as duas classes.

se que aproximadamente 80 mil novos habitantes foram somados ao contingente da cidade. No entanto, neste período, o crescimento urbano caracteriza-se muito mais como um fenômeno vertical, visto que a área urbana não teve aumento considerável.

É importante ressaltar que os $9 \%$ da área urbana em 1975 representam um número subestimado, tendo em vista o método de classificação utilizado neste trabalho, o qual não considera espaços legais, mas sim áreas realmente ocupadas por construções ou modificadas pelo homem. Como, em 1975, a densidade de ocupação era consideravelmente menor, áreas legalmente urbanas foram classificadas como campo natural.

O crescimento vertical das cidades permite que áreas naturais fundamentais para manutenção dos ecossistemas não sejam degradadas pela urbanização. No entanto, o aumento da concentração humana promove vários efeitos sociais e ambientais negativos. Diversos trabalhos têm mostrado que a alta concentração populacional em áreas restritas causa a redução da qualidade de vida pela ausência de áreas verdes e recreativas, o aumento da poluição visual, sonora e atmosférica, a contaminação do ambiente devido à produção e manejo inadequado do lixo urbano, o aumento da criminalidade e da violência, entre outros (CALLAI, 1993; ROSSATO, 1993; ELARABY, 2002).

As áreas de floresta no município mantiveram-se estáveis desde 1975 até 1995, tendo aumentado desde então. A dinâmica dessas áreas está ligada com aquelas ocupadas pela agricultura e pela pecuária. Dados do inventário florestal do Rio Grande do Sul comprovam o aumento da cobertura florestal nos últimos anos em todo o Estado (RS, 2002).

As áreas de campo natural apresentam redução progressiva, enquanto o oposto ocorre com a classe urbano. As áreas de lavouras anuais no PUSM têm sido mantidas constantes desde 1975, com pequenos incrementos em anos de melhores condições agrícolas. A variação ocorrida na classe corpos d'água entre 1975 e 1995 é resultado de flutuações no volume d'água armazenado na barragem de captação de águas da CORSAN (Companhia Riograndense de Saneamento). O aumento da área desta classe em 2002 foi possível através da identificação de novas áreas inundadas (açudes) no PUSM, na classificação das imagens do mesmo ano.

Os resultados do cruzamento do mapa de potencial de uso urbano das terras e dos mapas de uso para os diferentes períodos são também apresentados na tabela 1 . Os conflitos de uso das terras estão atrelados aos seus diferentes tipos de uso, sendo assim, observando-se os dados de 1975 a 2002, verificase que o aumento das áreas urbanas e a redução das áreas de campo natural foram os responsáveis pela elevação das áreas sob uso inadequado. Os problemas 
de uso das terras no PUSM estão relacionados com a utilização de áreas de várzeas e banhados ou com áreas que apresentam material geológico suscetível à contaminação da água subterrânea quando destinadas para construções urbanas e descartes de resíduos.

$\mathrm{O}$ uso das terras inadequadamente para construções urbanas tem sido apontado por MACIEL FILHO (1988 e 1990). Diversas áreas do PUSM apresentam material geológico formado de arenito (do tipo aqüífero), das Formações Santa Maria, Caturrita e Botucatu, com pequena capacidade de retenção de poluentes e, portanto, alto potencial para contaminação de águas subterrâneas. Considerando que a densidade urbana aumentou, de 1975 a 2002, sobre estes materiais areníticos frágeis, torna-se provável o aumento paralelo deste problema. Além disso, a remoção da cobertura pedológica para construções urbanas aumenta ainda mais os riscos de contaminação do lençol freático, haja vista que os solos possuem a capacidade de reter e transformar substâncias potencialmente perigosas (AZEVEDO \& DALMOLIN, 2004).

A utilização de várzeas e banhados para construções urbanas e descarte de resíduos também é outro caso de inadequação de uso das terras no PUSM. Segundo o levantamento semidetalhado de solos (PEDRON, 2005), esses ambientes apresentam predomínio de Planossolos Háplicos, Neossolos Flúvicos e Gleissolos Háplicos. Tais solos são caracterizados pela espessura variável, com horizonte superficial de textura arenosa, ocorrendo em áreas com saturação hídrica durante boa parte do ano, em relevos planos a suave ondulados, sendo formados sob depósitos fluviais de várzeas. As limitações desses materiais devem-se à baixa estabilidade para obras civis, suscetibilidade a inundações, solapamentos e contaminação de águas subterrâneas.

Da mesma forma, o uso incorreto de solos bem drenados existentes nas coxilhas sedimentares pode provocar sérios problemas ambientais. A classe dos Argissolos compreende 69\% do PUSM e apresenta grande variabilidade morfológica, física e química, que afeta o seu potencial de uso (PEDRON, 2005). Esta classe de solo apresenta alta suscetibilidade à degradação ambiental quando manejada inadequadamente, principalmente, em razão da erosão hídrica. Em parte do PUSM, principalmente em áreas ainda não impermeabilizadas, esses solos apresentam risco à ocupação humana, impresso pela sua fragilidade ao voçorocamento, tornando-se inaptos ao assentamento urbano e descarte de resíduos.

Analisando o crescimento demográfico de Santa Maria e a sua relação com as áreas sob uso inadequado e as áreas urbanas, verificou-se uma correlação linear positiva para ambas as simulações ( $r=0,90$ e $r=0,95$, respectivamente). A regressão mostra que existe uma tendência logarítmica para as duas relações testadas ( $\mathrm{y}=14,488 . \operatorname{Ln}(\mathrm{x})$ - 43,612 e $\mathrm{y}=21,841 . \operatorname{Ln}(\mathrm{x})-85,931$, respectivamente), confirmando o predomínio do crescimento vertical da cidade sobre o horizontal, sendo que onde atualmente, poucas novas áreas são adicionadas ao meio urbano em comparação com duas décadas atrás.

A configuração espacial de uso das terras e de conflitos de uso das terras para as diferentes épocas avaliadas são apresentados nos mapas das figuras $2 \mathrm{e}$ 3. Observa-se, nestes mapas, que a distribuição da área urbana ocorre no sentido leste - oeste, porque apresenta ao norte os morros do rebordo do Planalto, que se constituem em barreira física à expansão urbana, e ao sul, áreas federais pertencentes ao exército e à universidade. Na última década, como pode ser visualizado na figura 3, a expansão urbana tem ocorrido mais intensamente ao longo das rodovias BR 287 (sentido leste - oeste) e BR 392 (sentido sudoeste).

De acordo com URRUTIA (2002), a configuração atual de Santa Maria é consequiência da falta de planejamento, da especulação imobiliária e do crescimento demográfico desordenado ocorrido a partir da década de 60 , com a instalação da universidade federal, da base aérea e das unidades militares do exército, destacando o município nas atividades educacionais, militares e hospitalares da região. CANEPARO (2000), estudando a dinâmica de ocupação antrópica em Paranaguá - PR, também verificou que a configuração urbana é resultado, em grande parte, da especulação imobiliária.

O censo realizado pelo IBGE em 2000, nos municípios brasileiros, revela a presença de assentamentos irregulares em quase $100 \%$ das cidades com mais de 500 mil habitantes e também, ainda que em menor escala, nas cidades médias e pequenas (BRASIL, 2004). Em Santa Maria, existem loteamentos irregulares que ocorrem em áreas de proteção ambiental frágeis à ocupação humana (ROBAINA et al., 2001). De acordo com o levantamento de solos (PEDRON, 2005), nessas áreas, ocorre predomínio de Neossolos Litólicos e Neossolos Regolíticos, ambos sobre relevo ondulado a escarpado. Estes solos apresentam horizonte A raso sobre a rocha matriz consolidada ou parcialmente alterada, neste caso o basalto, caracterizando-se pela alta suscetibilidade à erosão hídrica, devido a sua morfologia e relevo, e pelas restrições à ocupação urbana devido à pouca espessura do solo, aos afloramentos rochosos e às declividades acentuadas (STRECK et al., 2002; GHERARDI et al., 2003). 


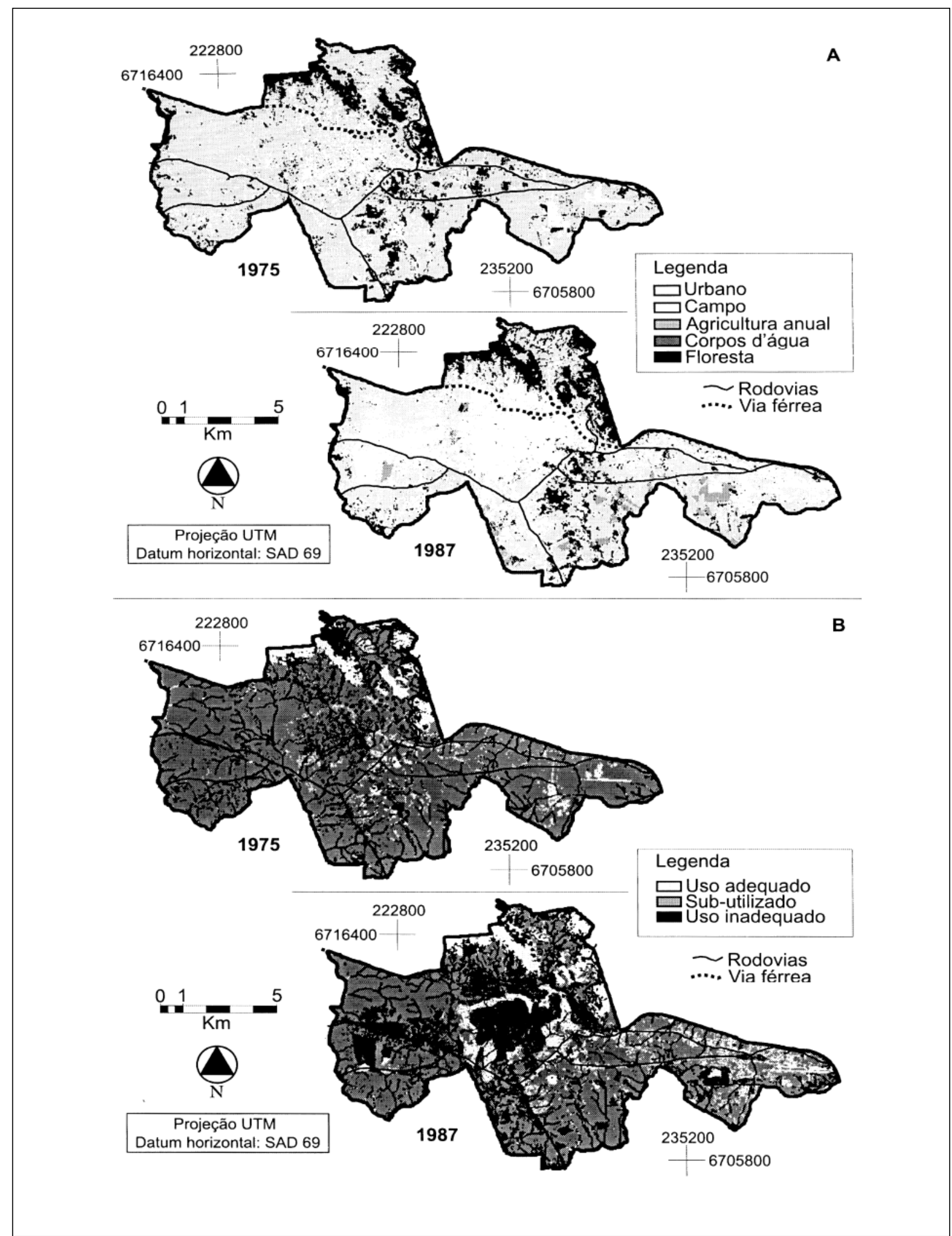

Figura 2 - Mapas de uso das terras em 1975 e em 1987 (A) e mapas de conflitos de uso das terras em 1975 e em 1987 (B) do perímetro urbano de Santa Maria, RS.

Ciência Rural, v.36, n.6, nov-dez, 2006. 


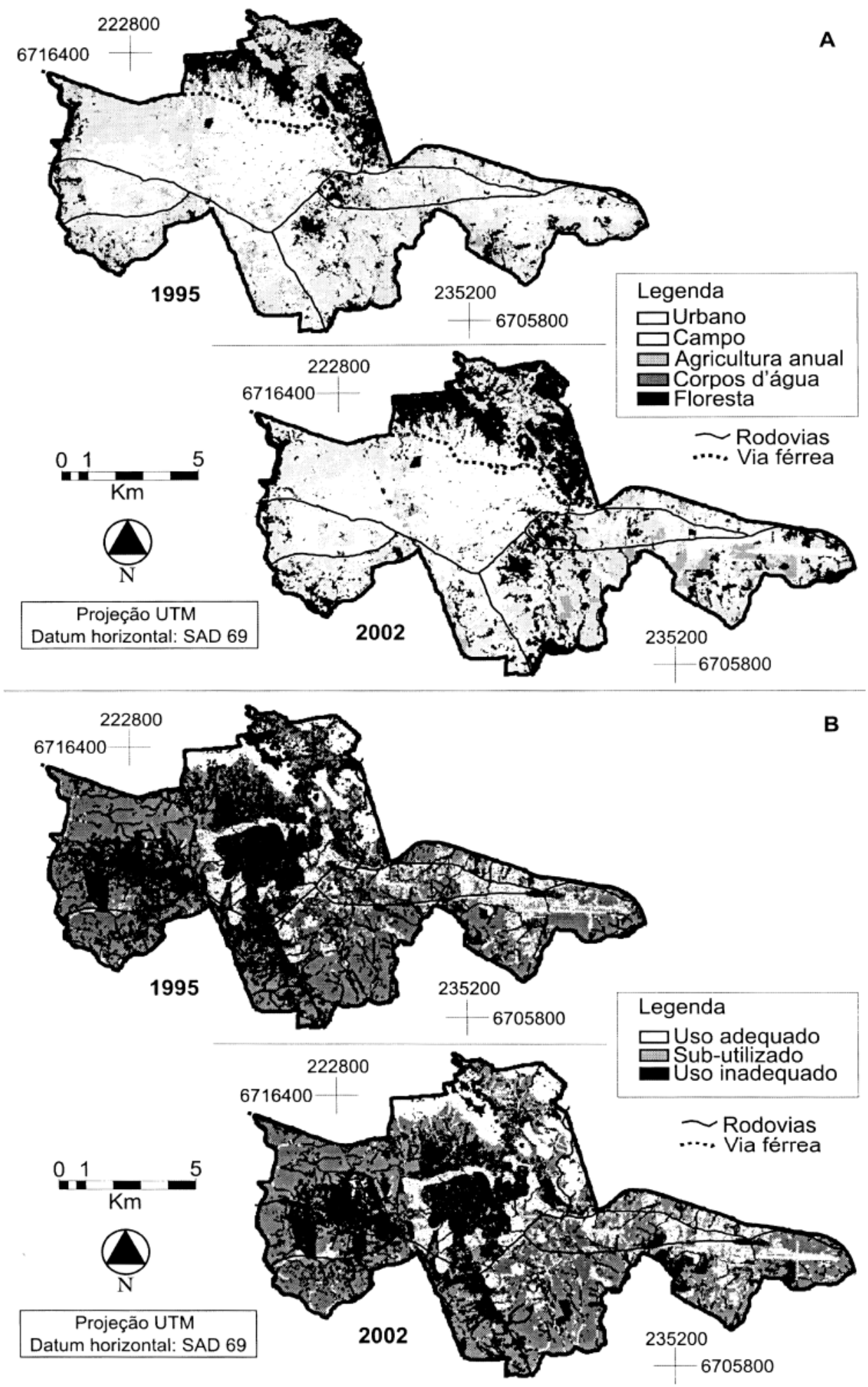

Figura 3 - Mapas de uso das terras em 1995 e em 2002 (A) e mapas de conflitos de uso das terras em 1995 e em 2002 (B) do perímetro urbano de Santa Maria, RS.

Ciência Rural, v.36, n.6, nov-dez, 2006. 
Segundo PINHEIRO (2004), os riscos oferecidos por áreas de encostas são resultantes da pressão antrópica sobre ambientes com baixo potencial de uso. A ocupação urbana dessas áreas promove diversas alterações, comprometendo, principalmente, a estrutura física do ecossistema local. Os principais problemas, nesse caso, estão relacionados com a contaminação dos solos e das águas pelo descarte inadequado de lixo e de esgotos e pela erosão e deslizamentos ocasionados por movimentos de massas provocados pela concentração dos fluxos de drenagens e de aterros domésticos instáveis.

\section{CONCLUSÕES}

O uso urbano das terras no Perímetro Urbano de Santa Maria, no período de 1975 a 2002, expandiu de 9 para $33 \%$. Os conflitos de uso das terras tiveram crescimento de $19 \%$, em 1975 , para $37 \%$, em 1995, reduzindo-se então para $33 \%$, em 2002, e estão associados ao crescimento populacional e das áreas construídas sobre locais frágeis. Essa redução deu-se, em parte, pelo aumento das áreas de floresta na última década no PUSM, e, em parte, pelo predomínio da expansão vertical sobre a horizontal. Os principais problemas de conflitos ambientais do uso das terras estão relacionados à utilização de áreas que apresentam material geológico do tipo aqüífero, suscetível à contaminação, e a utilização de áreas que possuem solos suscetíveis à erosão e àcontaminação, como alguns Argissolos, Planossolos e Neossolos, quando utilizados para construções urbanas e ou descarte de resíduos.

\section{REFERÊNCIAS}

AZEVEDO, A.C.; DALMOLIN, R.S.D. Solos e ambiente: uma introdução. Santa Maria: Pallotti, 2004. 100p.

BERGER, M.G. Uso do sensoriamento remoto na hierarquização das áreas de risco ambiental na subbacia hidrográfica do arroio Cadena, município de Santa Maria, RS. 2001. 144f. Dissertação (Mestrado em Engenharia Agrícola) - Programa de Pós-graduação em Engenharia Agrícola, Universidade Federal de Santa Maria.

BRASIL. Ministério das Cidades. Política nacional de desenvolvimento urbano. 2004. 92p. (Cadernos MCidades Desenvolvimento 1). Capturado em 14 jan. 2005. Online. Disponível na Internet: http://www.cidades.gov.br/

BURIOL, G.A. et al. Cartas mensais e anuais das temperaturas médias, das médias das temperaturas máximas e das médias das temperaturas mínimas do estado do Rio Grande do Sul. Revista do Centro de Ciências Rurais, Santa Maria, v.9, np, 1979. (Suplemento).
CALLAI, H.C. A cidade e a (re)criação da relação homem natureza. Ciência \& Ambiente, Santa Maria, v.4, n.7, p.4353, 1993.

CAMARA, G. et al. SPRING: Integrating remote sensing and GIS by object-oriented data modelling. Computers \& Graphics, v.20, n.3, p.395-403, 1996.

CANEPARO, S.C. Análise da dinâmica espacial da ocupação antrópica em Paranaguá/PR (1952 - 1996), através do uso de sistema de informações geográficas. R RA'EGA, Curitiba, n.4, p.111-130, 2000.

DA COSTA, S.M.F.; CINTRA, J.P. Environmental analysis of metropolitan areas in Brazil. Photogrammetry \& Remote Sensing, v.54, p.41-49, 1999.

EL ARABY, M. Urban growth and environmental degradation, the case of Cairo, Egypt. Cities, v.19, n.6, p.389-400, 2002.

GHERARDI, B. et al. Levantamento pedológico como base para o planejamento urbano no município de Piracicaba. In: CONGRESSO BRASILEIRO DE CIÊNCIA DO SOLO, 29., 2003, Ribeirão Preto, SP. Anais... Ribeirão Preto: SBCS, 2003. 4p. CD-ROM.

HATHOUT, S. The use of GIS for monitoring and predicting urban growth in East and West St Paul, Winnipeg, Manitoba, Canada. Journal of Environmental Management, v.66, p.229-238, 2002.

IBGE. Instituto Brasileiro de Geografia e Estatística. Dados do Censo Demográfico 2000 para o município de Santa Maria, RS. Capturado em 13 jan. 2005. Online. Disponível na Internet: http://www.ibge.gov.br

INPE. Instituto Nacional de Pesquisas Espaciais. Sistema de Processamento de Informações Georeferenciadas, release 4.0 - Sistema de ajuda on-line do SPRING. São José dos Campos: INPE, 2003. CD-ROM.

LÓPEZ, E. et al. Predicting land-cover and land-use change inte urban fringe a case in Morelia city, Mexico. Landscape and Urban Planning, v.55, p.271-285, 2001.

MACIEL FILHO, C.L. Uma proposta para evitar a poluição por lixo e esgoto doméstico. Ciência e Natura, Santa Maria, v.10, p.49-56, 1988.

MACIEL FILHO, C.L. Carta geotécnica de Santa Maria. Santa Maria: UFSM, 1990. 21p.

PEDRON, F. de A. Classificação do potencial de uso das terras no perímetro urbano de Santa Maria - RS. 2005. 74f. Dissertação (Mestrado em Ciência do Solo) - Programa de Pós-graduação em Ciência do Solo, Universidade Federal de Santa Maria

PEDRON, F. de A. et al. Sistema de avaliação do potencial de uso urbano das terras - SAPUT. In. CONGRESSO BRASILEIRO DE CIÊNCIA DO SOLO, 30., 2005, Recife, PE. Anais... Recife: SBCS, 2005. 4p. CD-ROM.

PEDRON, F. de A. et al. Utilização do sistema de avaliação do potencial de uso urbano das terras no diagnóstico ambiental do 
município de Santa Maria - RS. Ciência Rural, Santa Maria, v.36, n.2, p.468-477, 2006.

PINHEIRO, R.J.B. Impactos das atividades humanas sobre o solo - atividades urbanas. In: AZEVEDO, A.C. et al. Solos \& ambiente - I Fórum. Santa Maria: Pallotti, 2004. p.119144 .

ROBAINA, L.E. et al. Análise dos ambientes urbanos de risco do município de Santa Maria - RS. Ciência \& Natura, Santa Maria, v.23, p.139-152, 2001.

ROSSATO, R. Cidades brasileiras: a urbanização patológica. Ciência \& Ambiente, Santa Maria, v.7, p.23-32, 1993.

RS. Governo do Estado do Rio Grande do Sul. Inventário florestal contínuo do Rio Grande do Sul. Porto Alegre: SEMA, 2002. 15p.
STAT SOFT. Statistica (Data Analysis Software System), version 6, Tulsa - USA, 2001. CD-ROM.

STRECK, E.V. et al. Solos do Rio Grande do Sul. Porto Alegre: Emater/RS - UFRGS, 2002. 126p.

THOMLINSON, J.R.; RIVERA, L.Y. Suburban growth in Luquillo, Puerto Rico: some consequences of development on natural and semi-natural systems. Landscape and Urban Planning, v.49, p.15-23, 2000.

URRUTIA, R.A. Urbanização: crescimento da área urbana, espaços ociosos e especulação imobiliária no município de Santa Maria - 1980/2000. 2002. $65 \mathrm{f}$. Monografia (Especialização em História do Brasil) - Programa de Pós-graduação em História do Brasil, Universidade Federal de Santa Maria. 